\title{
EARLINET VALIDATION OF CATS L2 PRODUCT
}

\author{
Emmanouil Proestakis ${ }^{1,2, *}$, Vassilis Amiridis ${ }^{1}$, Michael Kottas ${ }^{1}$, Eleni Marinou ${ }^{1,3}$, Ioannis \\ Binietoglou $^{1,4}$, Albert Ansmann ${ }^{5}$, Ulla Wandinger ${ }^{5}$, John Yorks ${ }^{6}$, Edward Nowottnick ${ }^{7}$, Abduvosit \\ Makhmudov $^{8}$, Alexandros Papayannis ${ }^{9}$, Aleksander Pietruczuk ${ }^{10}$, Anna Gialitaki ${ }^{1,11}$, Arnoud \\ Apituley $^{12}$, Constantino Muñoz-Porcar ${ }^{13}$, Daniele Bortoli ${ }^{14}$, Davide Dionisi ${ }^{15}$, Dietrich Althausen ${ }^{5}$, \\ Dimitra Mamali $^{16}$, Dimitris Balis ${ }^{3}$, Doina Nicolae ${ }^{4}$, Eleni Tetoni ${ }^{111}$, Gian Luigi Liberti ${ }^{15}$, Holger \\ Baars $^{5}$, Iwona S. Stachlewska ${ }^{17}$, Kalliopi-Artemis Voudouri ${ }^{3}$, Lucia Mona ${ }^{18}$, Maria Mylonaki ${ }^{9}$, \\ Maria Rita Perrone ${ }^{19,20}$, Maria João Costa ${ }^{14}$, Michael Sicard ${ }^{13,21}$, Nikolaos Papagiannopoulos ${ }^{18}$, \\ Nikolaos Siomos ${ }^{3}$, Pasquale Burlizzi ${ }^{19}$, Ronny Engelmann ${ }^{5}$, Sabur F. Abdullaev ${ }^{8}$, Julian Hofer ${ }^{5}$, \\ Gelsomina Pappalardo ${ }^{18}$ \\ ${ }^{1}$ IAASARS, National Observatory of Athens, Athens, 15236, Greece, *proestakis@noa.gr \\ ${ }^{2}$ Laboratory of Atmospheric Physics, Department of Physics, University of Patras, 26500, Greece \\ ${ }^{3}$ Department of Physics, Aristotle University of Thessaloniki, Thessaloniki, 54124, Greece \\ ${ }^{4}$ National Institute of R\&D for Optoelectronics, Magurele, Romania \\ ${ }^{5}$ Leibniz Institute for Tropospheric Research, Leipzig, 04318, Germany \\ ${ }^{6}$ NASA Goddard Space Flight Center, Greenbelt, Maryland, USA \\ ${ }^{7}$ GESTAR, Universities Space Research Association, Columbia, Maryland, US \\ ${ }^{8}$ Physical Technical Institute of the Academy of Sciences of Tajikistan, Dushanbe, Tajikistan \\ ${ }^{9}$ Laser Remote Sensing Unit (LRSU) National Technical University of Athens Physics Department, Zografou, Greece \\ ${ }^{10}$ Institute of Geophysics PAS, Warsaw, Poland \\ ${ }^{11}$ University of Athens, School of Physics, Division of Environmental Physics-Meteorology, 15784, Athens, Greece \\ ${ }^{12}$ KNMI - Royal Netherlands Meteorological Institute, The Netherlands \\ ${ }^{13}$ Remote Sensing Laboratory, Universitat Politècnica de Catalunya, Barcelona, Spain \\ ${ }^{14}$ Departamento de Física, Instituto de Ciências da Terra, Escola de Ciências e Tecnologia, Universidade de Évora, Évora, \\ Portugal \\ ${ }^{15}$ Consiglio Nazionale delle Ricerche, Istituto Scienze dell'Atmosfera e del Clima (CNR-ISAC), Rome-Tor Vergata, Italy \\ ${ }^{16}$ Department of Geoscience and Remote Sensing, TU Delft, Delft, The Netherlands \\ ${ }^{17}$ Institute of Geophysics, Faculty of Physics, University of Warsaw (IGFUW), 02-093 Warsaw, Poland \\ ${ }^{18}$ Istituto di Metodologie per l'Analisi Ambientale (CNR-IMAA), Tito scalo, Italy \\ ${ }^{19}$ Dipartimento di Matematica e Fisica, Università del Salento, Lecce, Italy \\ ${ }^{20}$ CNISM-Consorzio Nazionale Interuniversitario per le Scienze Fisiche della Materia, Lecce, Italy \\ ${ }^{21}$ CiènInstitut d'Estudis Espacials de Catalunya (CTE-CRAE / IEEC), Universitat Politècnica de Catalunya, Barcelona, Spain
}

\begin{abstract}
The Cloud-Aerosol Transport System (CATS) onboard the International Space Station (ISS), is a lidar system providing vertically resolved aerosol and cloud profiles since February 2015. In this study, the CATS aerosol product is validated against the aerosol profiles provided by the European Aerosol Research Lidar Network (EARLINET). This validation activity is based on collocated CATS-EARLINET measurements and the comparison of the particle backscatter coefficient at $1064 \mathrm{~nm}$.
\end{abstract}

\section{INTRODUCTION}

The Cloud-Aerosol Transport System (CATS), a lidar remote sensing payload onboard the International Space Station (ISS), provides near- real-time profiles of aerosols and cloud optical properties [1]. Operating since February 2015, CATS's main objective is to study the 4D distribution, evolution, and transport of aerosols and clouds. Furthermore, CATS envisages to bridge space-borne lidar observations, between the Cloud-Aerosol Lidar and Infrared Pathfinder Satellite Observations (CALIPSO) and future space-borne lidars (e.g ESA's ADM-Aeolus and EarthCARE, NASA's ACE). The retrieval algorithms of CATS are similar to CALIPSO. In contrast with CALIPSO, CATS main products are the backscatter coefficient and depolarization ratio at $1064 \mathrm{~nm}$.

The aim of this study is to validate the CATS retrievals and establish the accuracy of the derived aerosol backscatter profiles. To this end, the lidar 
systems of the European Aerosol Research Lidar Network (EARLINET) [2], provide the ideal reference dataset. EARLINET consists of a large number of sophisticated lidars, which provide long-term quality-assured multi-wavelength aerosol retrievals. The objective of EARLINET is to provide a climatologically-significant profiling aerosol dataset.

In this study, we present and discuss the methodology for the validation of the profiles of CATS L2 backscatter coefficient at $1064 \mathrm{~nm}$ (Section 2). The methodology is demonstrated using a case study of a single CATS-ISS overpass over the Polly ${ }^{\mathrm{XT}}$ lidar of the National Observatory of Athens (NOA) on the 13th of January 2016 (Section 3.1). The approach followed is mostly based on the previous expertise and methodologies that have been developed and applied in EARLINET for the CALIPSO cal/val activity [3]. Finally, the first consolidated output from the comparison with a number of EARLINET stations is given in Section 3.2., while Section 4 provides our first conclusions.

\section{DATA AND METHODOLOGY}

At present, 13 EARLINET stations operating the $1064 \mathrm{~nm}$ channel contribute to this study. The permanent stations are located at: Athens (Greece), Barcelona (Spain), Belsk (Poland), Bucharest (Romania), Cabauw (Netherlands), Evora (Portugal), Lecce (Italy), Leipzig (Germany), Potenza (Italy), Rome (Italy) and Thessaloniki (Greece). Furthermore, the nonpermanent EARLINET stations at Dushanbe (Tajikistan) and the lidar system of NOA (Athens) have been integrated in the study.

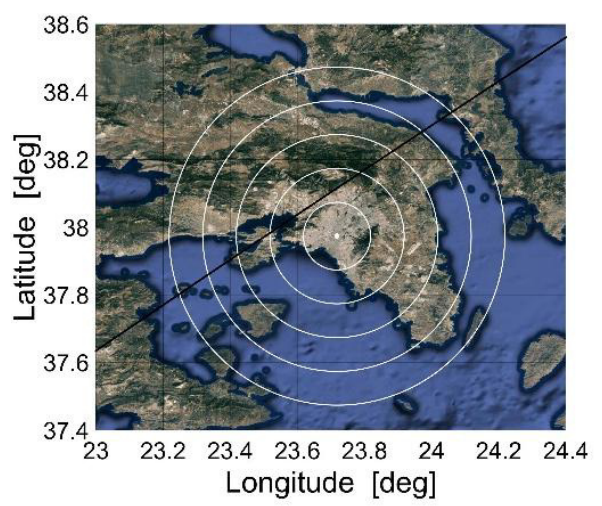

Figure 1. The nighttime ISS orbit over Athens on the $13^{\text {th }}$ of January 2016 (black line). The concentric white circles denote regions of radius $10,20,30,40$ and $50 \mathrm{~km}$ from the position of NOA-Polly ${ }^{\mathrm{XT}}$ lidar system.

For the purpose of demonstrating the methodology applied for the CATS validation, we use the NOA-Polly ${ }^{\mathrm{XT}}$ system, which was deployed at the Thiseion site of Athens, between May 2015 and March 2016, in the framework of the ACTRIS JRA1 campaign. The nighttime study case of the CATS-ISS overpass on the $13^{\text {th }}$ of January 2016 is shown in Fig.1.

\subsection{CATS-ISS}

CATS is a low cost payload onboard the ISS. Due to the ISS inclination orbit, CATS retrievals are confined in the geographical region between $51^{\circ} \mathrm{S}$ and $51^{\circ} \mathrm{N}$. CATS operates at $415 \mathrm{~km}$ altitude. The orbit characteristics of ISS enable CATS to provide information on the vertical structure of the atmosphere at different local times each day.

The CATS lidar was designed to operate in three different modes and in four different Instantaneous Fields Of View (IFOV). Mode 1 and Mode 3 are not operational due to a failure of the electronics of laser1 and to a problem related to the optical path respectively. Mode M7.2 is limited to the $1064 \mathrm{~nm}$ channel. The verticallyresolved retrievals of aerosol and clouds are provided in different processing levels [4]. In this study, EARLINET is utilized for the validation and exploitation of CATS M7.2 L2 of the V1-05 version of data.

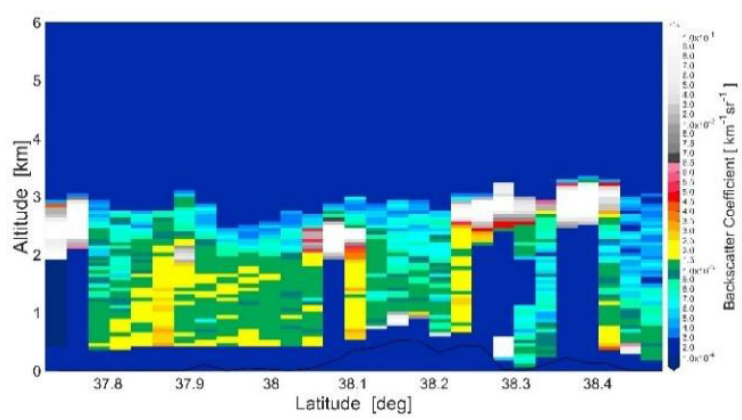

Figure 2. CATS Backscatter Coefficient $1064 \mathrm{~nm}$ of the overpass on the 2016-01-13,01:16:38 UTC.

CATS L2 product provides information on aerosols and clouds along the ISS track, with $5 \mathrm{~km}$ horizontal and $60 \mathrm{~m}$ vertical resolution, for the altitudinal range between 28 and $-2 \mathrm{~km}$. L2 product includes the backscatter coefficient at 
$1064 \mathrm{~nm}$, the Feature Type, Aerosol Subtype and the confidence of the classification are provided. The total backscatter coefficient at $1064 \mathrm{~nm}$ of the CATS overpass of the study case on the $13^{\text {th }}$ of January 2016 is shown in Fig.2.

For the comparison of the correlative backscatter coefficient dataset between CATS and groundbased lidars, cases that are not contaminated by clouds are selected. Regarding the accuracy of the classification of the cloud and aerosol layers, a Cloud-Aerosol Discrimination (CAD) score is assigned to the identified atmospheric layers.

\subsection{A typical EARLINET system}

Fig. 3 shows an example of EARLINET lidar quicklooks, providing the range-corrected signal time-height plot at $1064 \mathrm{~nm}\left(13^{\text {th }}\right.$ of January 2016). In the example presented here, the sky above the Athens site was contaminated by clouds during the ISS overpass. Thus the time averaging window of the lidar signal is shifted for few minutes after the satellite overpass, in order to avoid cloud presence.

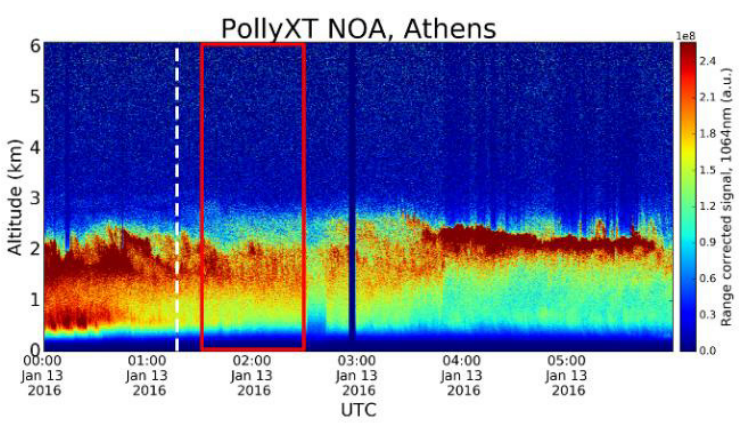

Figure 3. The range corrected signal time-series for the Polly ${ }^{X T} 1064 n m$ channel. The red box depicts the temporal averaging of the lidar signals for the selected scene (01:30-02:28), while the white dashed line indicates the CATS overpass time.

\section{RESULTS}

\subsection{EARLINET-CATS comparison: 2016- 01-13, 01:16:38 UTC}

CATS L2 backscatter profiles within a region of $50 \mathrm{~km}$ radius from the ground-based lidar are spatially averaged into a mean CATS profile. $\mathrm{CAD}$ score equal to -5 has been used for filtering out of the analysis the low confidence aerosol layers, which are possibly misclassified or contaminated by clouds. Accordingly, the mean backscatter profile is computed through the temporal averaging of the lidar signal. Fig.4 shows the comparison between the averaged Backscatter profiles of CATS and Polly ${ }^{\mathrm{XT}}$ groundbased system. The CATS error-bars shown correspond to the standard deviation from spatially averaging the CATS scene. Regarding EARLINET, typical uncertainties are in the range of $5-10 \%$ for the backscatter coefficient retrieved with the Raman method.

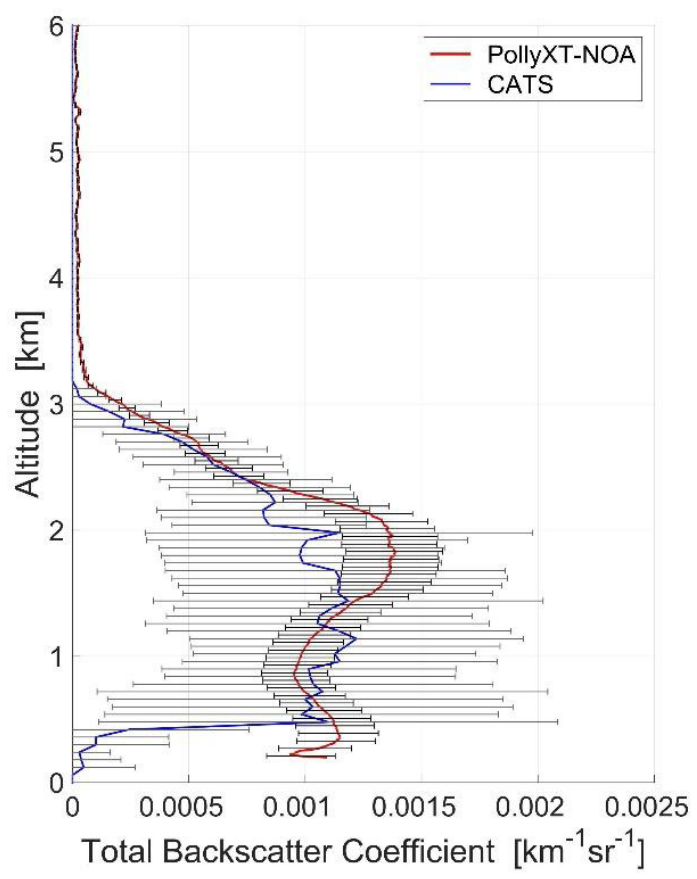

Figure 4. CATS (blue line) and EARLINET (red line) mean profiles of backscatter coefficient at $1064 \mathrm{~nm}$.

From the analysis of the $13^{\text {th }}$ of January 2016, it is observed that under homogeneous, relatively cloud free, nighttime conditions, the mean Backscatter Coefficient Profile at 1064 nm retrieved by CATS is in good agreement with the profile retrieved by the ground-based lidar. The comparison demonstrates a good nighttime performance of CATS. The observed disagreements to low altitudes (below $0.4 \mathrm{~km}$ ) are most probably attributed to the effect of the orography in the spatial window used for averaging.

\subsection{EARLINET-CATS comparison}

The distribution of the absolute differences between CATS and the EARLINET stations of Leipzig (13 cases), Dushanbe (5 cases) and NOA 
(4 cases), for nighttime ISS overpasses and for the altitudinal range between 0 and $10 \mathrm{~km}$ a.s.l., is shown in Fig.5. EARLINET measurements lower than the CATS minimum nighttime detectable backscatter limit $\left(5 \mathrm{e}-05 \mathrm{~km}^{-1} \mathrm{sr}^{-1}\right)$ are rejected from our analysis, for the same cases that CATS measurement provides values equal to zero as well. Based on the nighttime cases, the distribution of the absolute differences is characterized by mean value of $-1.519 \mathrm{e}-04 \mathrm{~km}^{-1} \mathrm{sr}^{-}$ ${ }^{1}$, median value of $-9.94 \mathrm{e}-05 \mathrm{~km}^{-1} \mathrm{sr}^{-1} 1$ and standard deviation of $6.634 \mathrm{e}-04 \mathrm{~km}^{-1} \mathrm{sr}^{-1}$.

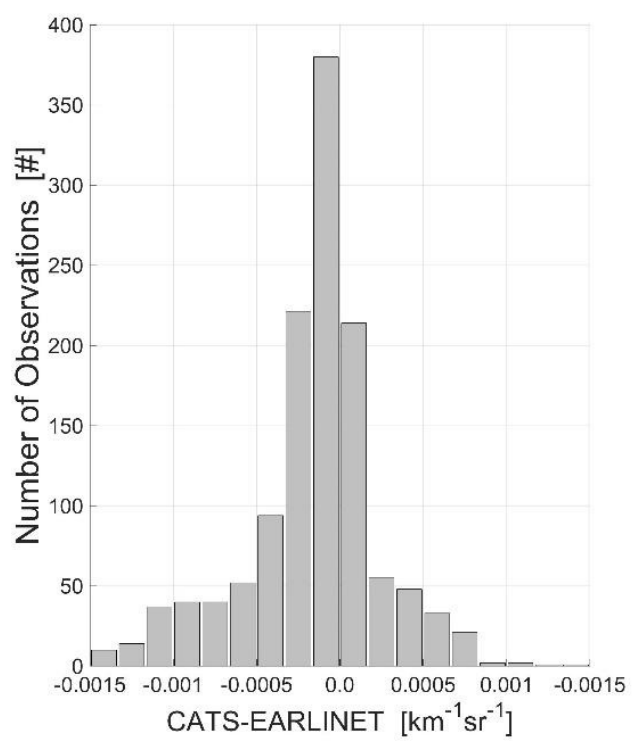

Figure 5. Distribution of the mean absolute differences between CATS and EARLINET backscatter measurements of Leipzig, Dushanbe and NOA stations and nighttime ISS overpasses.

The observed disagreements are most probably related to CATS minimum detectable backscatter, to the incomplete overlap of the ground-based lidars for lower altitudes, to the effect of the orography on CATS spatial averaging and to the horizontal distance between CATS footprint and the location of the EARLINET stations.

\section{CONCLUSIONS}

EARLINET is utilized for the validation study of CATS L2 backscatter profiles at $1064 \mathrm{~nm}$. Results demonstrate the good performance of CATS during nighttime conditions. The distribution of the absolute differences between CATS and EARLINET, for all the correlative measurements, is characterized by a mean value of $-1.518 \mathrm{e}-04$ $\mathrm{km}^{-1} \mathrm{sr}^{-1}$, a median value of $-9.94 \mathrm{e}-05 \mathrm{~km}^{-1} \mathrm{sr}^{-1}$ and a standard deviation of $6.634 \mathrm{e}-04 \mathrm{~km}^{-1} \mathrm{sr}^{-1}$. Future work includes the integration of the entire EARLINET network in this study. Furthermore the study will be expanded to include the CATSEARLINET daytime intercomparison.

\section{ACKNOWLEDGEMENTS}

The authors acknowledge ACTRIS-2 under grant agreement no. 654109 from the European Union's Horizon 2020 research and innovation programme. The research leading to these results has received funding from the European Union's Horizon 2020 Research and Innovation programme under grant agreement No 602014, project ECARS. The ISS NASA Research Office (NRO) funded the CATS instrument. CATS browse images and data products are freely distributed via the CATS web site at http://cats.gsfc.nasa.gov/data/.

\section{References}

[1] McGill, M. J., J. E. Yorks, V. S. Scott, A. W. Kupchock, and P. A. Selmer (2015), The Cloud Aerosol Transport System (CATS): A technology demonstration on the International Space Station, Proc. SPIE 9612, Lidar Remote Sensing for Environmental Monitoring XV, 96120A, doi:10.1117/12.2190841.

[2] Pappalardo, G., Amodeo, A., Apituley, A., Comeron A., Freudenthaler, V., Linné, H., Ansmann, A., Bösenberg, J., D’Amico, G., Mattis, I., Mona, L., Wandinger, U., Amiridis, V., AladosArboledas, L., Nicolae, D., and Wiegner, M.: EARLINET: towards an advanced sustainable European aerosol lidar network, Atmos. Meas. Tech., 7, 2389-2409, doi:10.5194/amt-7-23892014, 2014.

[3] Pappalardo, G., Wandinger, U., Mona, L., Hiebsch, A., Mattis, I., Amodeo, A., Ansmann, A., Seifert, P., Linné, H., Apituley, A., Alados Arboledas, L., Balis, D., Chaikovsky, A., D'Amico, G., De Tomasi, F., Freudenthaler, V., Giannakaki, E., Giunta, A., Grigorov, I., Iarlori, M., Madonna, F., Mamouri, R., Nasti, L., Papayannis, A., Pietruczuk, A., Pujadas, M., Rizi, V., Rocadenbosch, F., Russo, F., Schnell, F., Spinelli, N., Wang, X., and Wiegner, M.: EARLINET correlative measurements for CALIPSO: first intercomparison results, J. Geophys. Res., 115, D00H19, doi:10.1029/2009JD012147, 2010. 
[4] Yorks, J. E., M. J. McGill, S. P. Palm, D. L. Hlavka, P. A. Selmer, E. P. Nowottnick, M. A. Vaughan, S. D. Rodier, and W. D. Hart (2016): An overview of the CATS level 1 processing algorithms and data products, Geophys. Res. Lett., 43, 46324639, doi:10.1002/2016GL068006. 